\title{
O PROCESSO DE OCUPAÇÃO/RECUPERAÇÃO DE FÁBRICAS OCUPADAS NA AMÉRICA LATINA
}

\author{
Giane Maria de Souza* \\ Teresinha de Fátima Nunes ${ }^{* *}$
}

\section{RESUMO:}

Este artigo discorre sobre o processo de ocupação e recuperação das fábricas comandadas por trabalhadores na América Latina - Argentina, Brasil, Bolívia, Uruguai e Venezuela - a partir do Encontro Pan-americano em Defesa do Emprego, dos Direitos, da Reforma Agrária e do Parque Fabril, realizado em Joinville (SC) no ano de 2006. Para tal, tomamos o materialismo histórico como referencial teórico metodológico para compreender os antagonismos atuais da nova configuração do movimento operário latino-americano perante as novas crises do capitalismo neste início de século. Destarte, foram realizadas entrevistas com diversas lideranças internacionais das fábricas ocupadas e recuperadas. Constatou-se, assim, que há uma similaridade no processo de ocupação em virtude das condições estruturais pelas quais passa o capitalismo na América Latina. Por sua vez, no que se refere à recuperação há divergências crucias sobre a forma de gestão e a institucionalização das fábricas em relação ao Estado.

Palavras-chave: América Latina. Fábricas ocupadas. Movimento operário.

\section{THE PROCESS OF OCCUPATION / RECOVERY OF PLANTS EMPLOYED IN LATIN AMERICA}

\begin{abstract}
:
This article is about the occupation and recovering of the factories under the control of the Latin American workers :Argentina, Brazil, Bolivia, Uruguay and Venezuela ; written from the perspectives of the Pan American Meeting in defense of the Work, Rights, Agrarian Reform and Manufacter Park, carried out in Joinville (SC) in 2006. For that, we took the historic materialism as a methodological theorical reference to understand, nowadays, the antagonisms in the new configuration of the factory workers Latin American movement facing the new crisis in the capitalism in this beginning of century. This way, interviews have been carried out with many international leaders of the factories occupied and recovered. It's been noticed that there is a similarity in the occupation process due to the structural conditions that the capitalism has been going through in Latin America. On the other hand, in relation to the recovering of the factories there are crucial diverging ideas about the way of management and State institutionalization of the factories.
\end{abstract}

Keywords: Latin America. Factories occupied. Factory workers.

\section{Introdução}

O presente artigo versa sobre a dialética das relações entre capital-trabalho e as estratégias estabelecidas pelos trabalhadores em fábricas ocupadas na América Latina para recuperar postos de trabalho no atual contexto da reestruturação produtiva -, a partir do Encontro Pan-americano em Defesa do Emprego, dos Direitos, da Reforma Agrária e do Parque Fabril ocorrido em Joinville (SC), em 2006 ${ }^{1}$. Participaram da organização desse encontro diversas entidades, fábricas recuperadas e movimentos sociais latino-americanos, cujo objetivo central foi a defesa do emprego e dos direitos trabalhistas. O evento foi 
realizado nas dependências da Cipla, empresa ocupada desde 2002 e recuperada pelos trabalhadores. Segundo os organizadores, esse encontro constituiu um marco de resposta à crise ao capitalismo global. ${ }^{2}$

Assim, procuramos compreender as contradições dessa nova realidade que desponta como perspectiva de construção de novas relações sociais. Isso considerando que o capitalismo monopolista, em meados do século XX, reformula e reconfigura as relações de produção estruturada no processo contraditório de ampliação do trabalho morto, em detrimento da ampliação do trabalho vivo.

O estudo aqui apresentado parte da consideração de que as fontes investigadas não contemplam a totalidade das partes do movimento de trabalhadores na América Latina, por tratar-se de um estudo incipiente e, portanto, fragmentado.

Pesquisar a realidade da relação capital-trabalho exige a contrastação das fontes com o movimento real e contraditório, que permeia as relações de classe no sistema capitalista. A tentativa analítica de como os dirigentes operários "defendem os postos de trabalho", "ocupam", "recuperam" e assumem a direção das empresas é relevante para o atual debate teórico-metodológico sobre a divisão social do trabalho (HOBSBAWM, 1998).

$\mathrm{Na}$ atual conjuntura econômica, de reestruturação produtiva e monopolização do capital, contradições são explicitadas no decorrer de algumas falas. A partir dessas formulações pergunta-se: as estratégias dos trabalhadores das fábricas recuperadas constituem efetivamente uma construção de ruptura com a autovalorização do capital, ou representa ela uma outra forma de recuperação da produção dentro da lógica da divisão social do trabalho no capitalismo?

O texto, enfim, apresenta algumas experiências concretas de empresas recuperadas na América Latina - nos países: Brasil, Argentina, Bolívia, Venezuela e Uruguai. A partir delas, constata-se que os dirigentes de algumas empresas declaram sua defesa e luta pela ruptura das relações econômicas e sociais existentes na sociedade capitalista, almejando a construção de novas relações com vistas ao socialismo.

\section{Crise estrutural e reestruturação produtiva}

A crise do capitalismo atual tem levado a classe trabalhadora a vivenciar inúmeros momentos de instabilidade em conseqüência da flexibilização dos direitos e da precarização das condições de trabalho. A destruição dos postos de trabalho ocorre em virtude das alterações da base tecnológica, de novas formas de gestão e do fechamento de empresas.

Conforme Mészáros (2002), o sociometabolismo do capital determina sua expansão e acumulação produtiva. Nesse sentido, as crises que o capitalismo apresenta são decorrentes da sua própria transformação histórica.

Quando trata do processo de acumulação e do desemprego estrutural, Marx afirma que: "O capital adicional, formado no curso da acumulação atrai, relativamente à sua grandeza, cada vez menos trabalhadores. E o velho capital periodicamente reproduzido com nova composição repele, cada vez mais, trabalhadores que antes empregava" (MARX, 1985, p. 730). Isso significa que o processo de acumulação "põe em movimento maior quantidade de trabalho sem recrutar mais trabalhadores" (ibidem).

Para que o capitalismo possa reproduzir-se e acumular não basta dispor de uma quantidade determinada de força de trabalho disponível, pelo aumento vegetativo na população, mas é necessária a formação de um exército industrial de reserva, responsável 
pela manutenção das relações de exploração e domínio do capital. Consequentemente há uma intensificação nas crises do sistema capitalista (idem, p. 737).

Hobsbawm (1995) considera que as décadas de 1970 e 1980 representaram um período de crise para o capitalismo. Por um lado, houve um agravamento massivo do desemprego; por outro lado, a expansão do capital continuava com sua lógica destrutiva. Esta nova crise - como historicamente o capitalismo se vem forjando -, do ponto de vista da existência contraditória do capital, seria cíclica. No entanto: "O crescente desemprego dessas décadas não foi simplesmente cíclico, mas estrutural. Os empregos perdidos no mau tempo não retornariam quando os tempos melhorassem: não voltariam jamais" (HOBSBAWM, 1995, p. 403).

Essa é a grande contradição do capitalismo no final do século XX. Essa lógica destrutiva não atinge somente os trabalhadores, mas todo o sistema, inclusive no interior do capital, provocando crises como o fechamento de empresas.

Do ponto de vista da expropriação da mais-valia e da divisão social do trabalho, a reestruturação produtiva mantém o pólo de existência do capital. Aquilo que dentro da historiografia econômica é classificado como uma passagem do taylorismo/fordismo para o toyotismo, nada mais é do que a reprodução sociometabólica do capital. (ANTUNES, 1999)

\section{Estratégias de ocupação e de recuperação}

Ao analisar as experiências das fábricas ocupadas e recuperadas na América Latina, percebemos que há uma similaridade no processo de ocupação no que se refere ao fechamento das fábricas e tomada dos meios de produção pelos trabalhadores. As empresas declaram sua falência dentro da ótica já ressaltada por Marx em seus textos. O capitalismo não se sustenta e gera no seu interior suas próprias crises, suas contradições essenciais para sua existência, afetando não só os trabalhadores como seu próprio mecanismo vital. A incorporação de tecnologia, o financiamento público estatal e o endividamento financeiro são apontados pelos trabalhadores como os causadores do fechamento das fábricas. Nesse sentido, há uma convergência prática de tomada dos meios de produção pelos trabalhadores, os quais assumem que esse processo de ocupação é gerado a partir dessas condições concretas apresentadas, condicionadas pela crise estrutural pela qual passa o capitalismo na América Latina.

Goulart (2006) explicita que no Brasil, nos últimos anos, muitas empresas faliram criando um verdadeiro "cemitério de postos de trabalho". Para responder a esse processo foram criados dois movimentos de organização de trabalhadores em fábricas recuperadas. O primeiro deles, cooperativas de trabalhadores (Associação Nacional de Empresas de Autogestão - ANTEAG, Cooperativa Central de Produção Industrial de Trabalhadores em Metalurgia - UNIFORJA e Universidade Solidária - UNISOL) foram organizadas pelos Sindicatos dos Metalúrgicos de São Bernardo do Campo e o Sindicato dos Sapateiros de Franca; o segundo deles é o Movimento das Fábricas Ocupadas em Luta, do qual Goulart é coordenador geral. Esse movimento compreende as empresas ocupadas e recuperadas: Cipla, Interfibras e Flaskô.

Do ponto de vista das relações de produção, Goulart (2006) justifica:

O problema é esse: se não tiver a produção funcionando, não vai vender produto, não vai ter salário [...] A fábrica, portanto, é uma fábrica capitalista. Todas as fábricas são capitalistas. Está dentro das relações de mercado, ela compra mercadoria e quer comprar o mais barato possível, em qualquer lugar. E ela vende o produto dela e quer vender o mais caro 
possível, e vender o máximo de produtos. As fábricas ocupadas agem assim também.

Os trabalhadores, como é possível identificar no discurso de Goulart (2006), ocupam as fábricas, porém não conseguem romper com as relações sociais de produção, tampouco com a divisão social do trabalho. Ao afirmar que as fábricas ocupadas pelos trabalhadores agem como qualquer empresa capitalista, o representante do movimento das fábricas ocupadas assume que é o mercado que determina as relações de produção, conseqüentemente a garantia de sobrevivência dessas fábricas. Se não houver demanda, não há produção, se não houver produção, não há salário.

Venturim (2006), representante da Cooperativa de Produção Gráfica de Montevidéu - Uruguai, relata que o patrão contraiu uma divida de 60 milhões de pesos, o que ocasionou a quebra e o fechamento da empresa. A partir de então 60 trabalhadores mantêm a fábrica ocupada com o propósito de "mostrar que os trabalhadores têm capacidade de gestionar uma empresa melhor que os capitalistas". Afirma que "o direito ao trabalho está acima do suposto direito de propriedade, porque direito de propriedade é direito dos meios de produção". Sendo assim, nada mais conveniente que os próprios trabalhadores tomarem para si o comando da empresa e o processo produtivo. Para esse dirigente a ruptura com as relações sociais de produção passam pela tomada de consciência dos trabalhadores:

[...] o capitalismo se sustenta justamente pelo atraso na consciência do trabalhador. Então o que ocorre quando se implanta uma cooperativa, na prática, não para estudantes, militantes, intelectuais etc., mas para a massa dos trabalhadores se dá conta de que está equivocado, de que não é necessário patrão, porque operário pensa que o patrão tem mais capacidade que ele, é mais inteligente, está mais preparado, e que por isso está mandando. Ele crê nisso. Porém quando se dá uma experiência como a nossa, que o patrão levou ao desastre uma empresa importante, uma empresa grande e ele passam pela experiência, que todas as coisas eles resolvem melhor que o patrão. Está aberta a sua consciência, que ele faz melhor que o patrão [...] Eles podem dizer: é possível as mudanças sociais, o socialismo é possível. Então entende que é esse o papel a cumprir, a experiência de uma cooperativa de produção.

Pela ótica das ocupações e da recuperação das empresas, vê-se que a análise do dirigente uruguaio, desse processo de tomada das fábricas, serve para instigar a tomada de consciência - a passagem da consciência em si para a consciência para si. Para ele o movimento dos trabalhadores serve para essa transição do conhecimento vulgar para um conhecimento concreto da realidade. Cria-se aí um processo não só de ocupação das fábricas, mas um processo gerador de consciência, possível de transformar-se em um movimento de ruptura.

Na Bolívia segue-se a mesma lógica de destruição do capital. Mansilha (2006), da Federação Sindical de Trabalhadores Mineiros da Bolívia, que reúne 23 mil trabalhadores assalariados de 57 empresas, cita como exemplo a tomada do controle de uma a empresa boliviana - Huanuni, maior produtora de estanho da Bolívia e uma das maiores do mundo. Essa mineradora sofreu uma descapitalização pela empresa inglesa RBG. Tratava-se de uma quebra fraudulenta. Os trabalhadores ocuparam a empresa e chegaram a expulsar os estrangeiros.

Relata que depois que os trabalhadores assumiram o controle da fábrica, descobriram que a empresa não estava quebrada, que havia lucrado abundantemente. 
Implantaram uma gestão com controle social e o governo auxiliou com empréstimo de 6 milhões de pesos bolivianos, que foram pagos em seis meses.

Em quatro anos após ocupação, até setembro de 2006 um lucro de 23 milhões de dólares. Esse lucro reverte à própria empresa (com mais de mil trabalhadores) para novos projetos. A empresa que tinha aproximadamente 10 anos de vida útil ampliou para no mínimo 40 anos. Isso significa que estão deixando para a próxima geração uma mina nova. Diz que essa experiência dessa cooperativa não custou um centavo ao estado da Bolívia nem a corporação mineira da Bolívia incluindo os custos com novos investimentos.

Nesse momento tem um desafio: conseguir com a participação do governo que os cooperativistas se convertam agora em trabalhadores assalariados. Antes éramos mil agora somos cinco mil trabalhadores assalariados. Desses cinco mil queremos quintuplicar, nesse caso com o tratado do mineral, criar mais postos de trabalho para os companheiros desempregados.

Dentro das perspectivas relatadas, a Federação Sindical de Trabalhadores Mineiros da Bolívia recupera uma empresa que antes era estatal, ocupam e hoje reclamam sua nacionalização novamente. Para os trabalhadores, depois de instituída a cooperativa houve um resgate da produção, um aumento acentuado de trabalhadores e um acréscimo dos lucros da empresa. A reivindicação dos bolivianos, pelo fato político, remete-se a transformar os trabalhadores cooperados em trabalhadores assalariados, resgatando a nacionalização da empresa ocupada e a estatização dos meios de produção.

Na Argentina, cerca de 200 empresas estão sob controle operário e contam com mais de 10 mil trabalhadores. A empresa capitalista selecionada para esse estudo foi um hotel construído com financiamento estatal em 1978, no centro de Buenos Aires.

Oliviero e Pensavalle (2001) explicam que a crise na Argentina no final do século XX provocou a falência do hotel encerrando suas atividades comerciais. Dois anos após, um grupo de aproximadamente 30 trabalhadores ocupou o hotel e resistiu. Após um processo muito intenso, aos poucos foram restaurando todo o hotel e iniciaram a trabalhar. Todo o financiamento conquistado foi para a reconstrução do hotel e para iniciar sua comercialização. Dos 30 companheiros iniciais, após quatro anos de ocupação, o Hotel Bauen é uma cooperativa com 160 sócios.

Oliviero e Pensavalle afirmam que divergem sobre a estatização:

Com relação à estatização tem uma pequena diferença, nós vamos pelo caminho possível. O que nós buscamos é: os meios de produção, as empresas nas mãos dos trabalhadores, entendemos isso como direito. As empresas nas mãos dos trabalhadores é nosso objetivo central. O Estado que temos não é um caminho real no momento. Vemos que o Estado não tem uma política no que diz respeito às empresas recuperadas, mas de cooptar alguns dirigentes, alguns representantes dos trabalhadores. Temos divergências com relação a esse entendimento: um exemplo tem empresa ocupada em que os trabalhadores entenderam que a ocupação se tratava de uma questão obreira, e que a cooperativa é uma coisa burguesa, capitalista, etc. Entendemos que esse é um argumento legal que temos em mãos, se nós tomarmos o argumento de cooperativa, evitamos a repressão e nos permite funcionar. Depois internamente funcionamos sob o ponto de vista obreiro. A diferença é de título, de uma palavra. (OLIVIERO, PENSAVALLE, 2006) 
Entendem que o controle da produção pelos trabalhadores somente pode ser mantido por meio da manutenção da cooperativa. A cooperativa tornou-se um meio legal de administrar a empresa e receber incentivos fiscais, bem como impedir represálias sobre seu funcionamento.

Oliviero e Pensavalle (2006) declaram que para a recuperação do hotel houve uma cooperação das fábricas ocupadas argentinas e de algumas universidades para a sua organização e administração. Oliviero relata que sua função antiga no hotel era de serviços gerais, hoje ele assume a tesouraria da cooperativa. Declara que todos recebem uma remuneração equivalente à arrecadação da empresa. Porque o hotel para ele é "responsabilidade de todos".

Na Venezuela, Nelson (2006) declara que existe em nível nacional mais de 800 empresas fechadas. Consequiências sucessivas das crises do capital no país. Justifica a manutenção dessa situação na conjuntura atual dizendo: "Muitas vezes os trabalhadores, como classe de trabalhadores, tem medo de confrontar, apesar de na Venezuela o presidente Chavez publicamente dizer que empresa fechada é empresa desapropriada".

Recentemente foi organizada a Frente de Trabalhadores de Empresas Recuperadas (FRETECO), que agrega atualmente 14 empresas, da qual Nelson é representante. Sobre a mobilização e a organização das ocupações declara que:

Sem dúvidas queremos que a massa trabalhadora geral, não necessariamente os trabalhadores das empresas ocupadas, no reunamos e debatemos sobre o modelo de país que queremos e assim aprofundemos a revolução, apoiando o governo nesse processo revolucionário [...] estamos discutindo com os companheiros da Cipla que é preciso começar preparar quadros para que esses quadros possam reproduzir esse conhecimento [...] precisamos formar grandes quadros sociopoliticos, bem como para transferir toda essa experiência que estamos tendo das fábricas ocupadas [...] para transformar toda essa mentalidade capitalista como protagonista de um processo histórico só se faz por meio da preparação sociopolítica. (NELSON, 2006)

Em janeiro de 2005 foi criada a lei das cooperativas, que garante a desapropriação e o controle parcial do Estado, com participação de $49 \%$ dos trabalhadores e $51 \%$ do Estado. Atualmente as organizações de trabalhadores estão defendendo a estatização total, porém sob controle dos trabalhadores.

Que o governo garanta o mercado venezuelano para vender seus produtos. Porque se sairmos a competir sabemos que a economia mundial esta sendo manipulada pela influência da China, Índia são países que estão globalizando a sua produção, estão abarcando o mercado mundial, portanto encerrar suas fronteiras comerciais, então temos que ter claro que o Estado também tem que dar garantias de que a empresa permaneça. Porém, importante também garantir uma rentabilidade social, uma rentabilidade de mercado. (NELSON, 2006)

\section{Conclusão}


Como foi apontado na introdução, o escopo deste artigo foi uma tentativa incipiente - dadas as condições objetivas da pesquisa - de analisar a relação trabalho-capital dentro do contexto das fábricas ocupadas em alguns países da América Latina.

Os dirigentes das fábricas ocupadas referem-se às condições materiais de crise do capitalismo que, indissociavelmente, se articulam e se assemelham no interior da classe trabalhadora e nas reconfigurações do capitalismo latino-americano. $\mathrm{O}$ processo de tomada de controle das fábricas - denominado pelos trabalhadores de ocupação - acontece de forma eqüitativa, porém a recuperação e o comando das fábricas são formas diferenciadas. Destacamos o caso uruguaio, no qual os trabalhadores continuam mantendo o controle dos meios de produção na perspectiva dialética de formação de consciência. Porém, muitas vezes a recuperação acontece dentro da lógica do capital e seu metabolismo.

Por meio das entrevistas analisadas pode-se constatar que dentro desse contexto há, efetivamente, uma nova reconfiguração da classe trabalhadora, que agora, no comando dos meios de produção, recupera a lógica capitalista de produção e comando, reproduzindo a divisão social do trabalho.

Porém, este estudo pretende finalmente abrir caminhos futuros, no escopo das contradições encontradas, para outras incursões dentro do debate teórico-metodológico do materialismo histórico, a partir da análise das fábricas ocupadas. Há concretamente um movimento forjando-se e assumindo que no entender marxiano se trata das velhas determinações históricas de reprodução da divisão social do trabalho e das relações sociais de produção.

\section{Referências}

ANTUNES, Ricardo. Adeus ao trabalho. Ensaio sobre as metamorfoses e a centralidade do mundo do trabalho. 6. ed. São Paulo: Cortez, 1999.

BRAVERMANN, Harry. Trabalho e capital monopolista: a degradação do trabalho no século XX. Rio de Janeiro. Livros Técnicos e Científicos, 1987.

GOULART, Serge. Entrevista. Concedida a Giane Maria de Souza. Joinville: s.ed., maio 2006.

HOBSBAWM, Eric. Era dos extremos. O breve século XX (1914-1918). São Paulo: Companhia das Letras, 1995.

Sobre a história. São Paulo: Companhia das Letras, 1998.

MANSILHA, Próspero Quister. Entrevista. Concedida a Giane Maria de Souza e Teresinha de Fátima Nunes. Joinville: s.ed., dez. 2006.

MARX, Karl. O capital. Crítica da economia política. Livro I, vol. II. São Paulo: Difel, 1985.

Capítulo VI inédito.Resultados do Processo de Produção Imediata. In: $\mathbf{O}$ capital. São Paulo: Moraes, 1985.

MÉSZÁROS, István. Para além do capital. São Paulo: Boitempo, 2002. 
OLIVIERO, Laurino; PENSAVALLE, Gerardo. Entrevista. Concedida a Giane Maria de Souza e Teresinha de Fátima Nunes. Joinville: s.ed., dez. 2006.

VENTURIM, Juan Carlos. Entrevista. Concedida a Giane Maria de Souza e Teresinha de Fátima Nunes. Joinville: s.ed., dez. 2006.

\footnotetext{
* Professora graduada em História pela Universidade da Região de Joinville. Mestre em História, Filosofia e Educação pela Universidade Estadual de Campinas. Especialista Cultural - Educadora de Museus na Estação da Memória. Professora no Curso de Arquitetura e Urbanismo Sociesc - Instituto Superior Tupy.

*** Professora, enfermeira graduada pela Universidade Federal de Santa Catarina, especialista em Saúde Pública e Saúde do Trabalhador, pela Escola Nacional de Saúde Pública (FIOCRUZ). Mestre em Engenharia de Produção - área de concentração em Ergonomia pela Universidade Federal de Santa Catarina.

${ }^{1} \mathrm{O}$ resultado dessa pesquisa foi apresentado no V Colóquio Marx e Engels na Universidade Estadual de Campinas em 2007 organizado pelo Centro de Estudos Marxistas - CEMARX.

${ }^{2}$ Em julho de 2007 o Ministério do Trabalho destituiu os trabalhadores da direção da fábrica, instituindo uma Comissão Provisória no comando da empresa para a transformação da mesma em sistema cooperativado nos moldes preconizados pelo governo federal. Foram inúmeras alegações ministeriais para a intervenção, entre elas, a acusação de corrupção, abuso e aparelhamento de poder (o comando da empresa estava sob o domínio de uma tendência interna do Partido dos Trabalhadores - O Trabalho).
}

Artigo recebido em: 13/12/2008

Aprovado para publicação em: 15/01/2009 